\title{
Earlier onset of the spring phytoplankton bloom in lakes of the temperate zone in a warmer climate
}

\author{
FRANK PEETERS*, DIETMAR STRAILE*, ANDREAS LORKE* and \\ DAVID M. LIVINGSTONE† \\ *Limnological Institute, University of Konstanz, Mainaustrasse 252, D-78464 Konstanz, Germany, †Water Resources Department, \\ Swiss Federal Institute of Aquatic Science and Technology (Eawag), Überlandstrasse 133, CH-8600 Dübendorf, Switzerland
}

\begin{abstract}
The decoupling of trophic interactions is potentially one of the most severe consequences of climate warming. In lakes and oceans the timing of phytoplankton blooms affects competition within the plankton community as well as food-web interactions with zooplankton and fish. Using Upper Lake Constance as an example, we present a model-based analysis that predicts that in a future warmer climate, the onset of the spring phytoplankton bloom will occur earlier in the year than it does at present. This is a result of the earlier occurrence of the transition from strong to weak vertical mixing in spring, and of the associated earlier onset of stratification. According to our simulations a shift in the timing of phytoplankton growth resulting from a consistently warmer climate will exceed that resulting from a single unusually warm year. The numerical simulations are complemented by a statistical analysis of long-term data from Upper Lake Constance which demonstrates that oligotrophication has a negligible effect on the timing of phytoplankton growth in spring and that an early onset of the spring phytoplankton bloom is associated with high air temperatures and low wind speeds.
\end{abstract}

Keywords: climate warming, lake, mixing, modelling, phytoplankton, spring bloom, stratification

Received 26 June 2006; revised version received 29 January 2007 and accepted 28 March 2007

\section{Introduction}

Statistical analysis of the biological effects of recent climate fluctuations has revealed that changes in climatic conditions result in shifts in the timing of the seasonal occurrence of various species, altering formerly synchronized interactions between the species, and also between the life cycles of individual organisms and their environment (Visser et al., 1998; Visser \& Hollemann, 2001; Beaugrand et al., 2003; Winder \& Schindler, 2004). Because decoupling trophic interactions from one another may have dramatic consequences for the entire food web (Cushing, 1990; Post et al., 1999; Stenseth \& Mysterud, 2002; Beaugrand et al., 2003), shifts in the phenology of individual species must be taken into account when predicting ecosystem behaviour in a future warmer climate.

In lakes and oceans at temperate latitudes, the complexity of the plankton community increases from winter to summer in an annually recurring pattern, the annual plankton succession (Sommer, 1989). At the base

Correspondence: Frank Peeters, tel. +49 753188 3459, fax +49 753188 3533, e-mail: Frank.Peeters@uni-konstanz.de of the food web, the phytoplankton, by converting solar energy to chemical energy and storing it as organic matter, provides the energy upon which the entire trophic system depends (Wetzel, 2001). The abrupt onset of phytoplankton growth in spring therefore determines the starting point for the plankton succession.

The timing of the onset of phytoplankton growth is determined predominantly by abiotic factors such as mixing conditions in the water column (which affect the exposure of algal cells to light), the seasonal variation in solar radiation and the duration of ice cover (Bleiker \& Schanz, 1989; Adrian et al., 1999; Tian et al., 2003; Sharples et al., 2006). In deep, ice-free lakes, interannual variations in the timing of the onset of phytoplankton growth result mainly from interannual variations in the timing of the transition from strong to weak turbulent mixing and much less from variations in water temperature or solar radiation, which have only a slight effect (Peeters et al., 2007). Climate warming will result in higher water temperatures, alter mixing conditions and affect thermal stratification (Stefan et al., 1998; Peeters et al., 2002; Livingstone, 2003; Danis et al., 2004).

Using Upper Lake Constance as an example, we here use numerical simulations to investigate the impact of 
climate warming on the timing of the spring phytoplankton bloom. A one-dimensional physical mixing model coupled to a phytoplankton-growth model and driven by meteorological data is used to simulate the vertical distributions of turbulent diffusivity, water temperature and phytoplankton biomass as functions of time. A reference simulation (REF) based on measured meteorological data is compared with simulations based on different climate scenarios. After a brief description of the mathematical model, the model implementation and operation, the climate scenarios employed and the data available for this study, we present the results of model simulations run under the different sets of meteorological conditions assumed in the scenarios. First we discuss the simulated effects of climate warming on the physical conditions pertaining in the lake and the implications of these effects for the timing of the onset of the spring phytoplankton bloom. These results are then compared with the findings from a statistical analysis of long-term data from Upper Lake Constance. Finally, we discuss the potential consequences of the predicted increase in water temperature and the shift in the timing of the onset of phytoplankton growth for the plankton succession.

\section{Study area and data}

\section{Upper Lake Constance}

Upper Lake Constance is a large, deep lake (surface area $472 \mathrm{~km}^{2}$, maximum depth $254 \mathrm{~m}$ ) situated at the northern edge of the western European Alps. It consists of a large eastern basin (Obersee, maximum depth $254 \mathrm{~m}$ ) and a smaller western basin (Überlinger See, maximum depth $144 \mathrm{~m}$ ) which is separated from Obersee by a sill that reaches up to $80 \mathrm{~m}$ below the lake surface. The upper $80 \mathrm{~m}$ of the lake thus form a continuous water layer with nearly homogenous conditions in the horizontal. Upper Lake Constance is monomictic in most years. The lake freezes over only very rarely; the last full ice cover occurred in 1963. Eutrophication caused by the input of anthropogenic phosphorus to the lake peaked in the 1970s (Güde et al., 1998). A subsequent reduction in phosphorus loading has resulted in the lake returning almost to its former oligotrophic status. The consequences of cultural eutrophication and oligotrophication for the plankton populations of the lake have been summarized in a recent set of articles (see Bäuerle \& Gaedke, 1998).

\section{Data set}

In the numerical modelling part of this study we focus on the time period 1979-1994. The meteorological data set employed consisted of hourly measurements of wind speed, wind direction, air temperature, solar radiation, relative humidity and cloud cover from the German National Meteorological Service station in Konstanz at a height of $17 \mathrm{~m}$ above ground and $54 \mathrm{~m}$ above the lake surface. Details on the preparation of the meteorological data for use in the model - e.g., on estimating the wind speed over open water and the solar radiation penetrating the lake surface - are given elsewhere (Peeters et al., 2007). The statistical analysis, which covered the period 1979-2006, employed daily mean air temperatures, daily maximum wind speeds and total daily sunshine duration from the same meteorological station in Konstanz.

Calibration of the hydrodynamic model was based on temperature profiles, measured at monthly to fortnightly intervals, that were available for the period 1979-1994 (Straile et al., 2003). Water temperature was measured at the deepest point of the lake at depths of 0 , $5,10,15,20,30,50,100,200$ and $250 \mathrm{~m}$ with a resolution of $0.1{ }^{\circ} \mathrm{C}$. The validation of the hydrodynamic model (see Peeters et al., 2007) was based on data from a thermistor chain installed at the central station of the Überlinger See basin. These data were measured at 20-min intervals with a resolution of $0.01{ }^{\circ} \mathrm{C}$.

Water samples for chlorophyll $a(\mathrm{Chl} a)$ analysis were collected in the central part of the Überlinger See basin at about 20 distinct depths between 0 and $60 \mathrm{~m}$. Chl $a$ was determined spectrometrically after extraction of the filtrate in hot ethanol and correction for phæopigments by acidification (Häse et al., 1998). Data were obtained at weekly intervals during the growing season and less frequently during the winter months. Chl $a$ data were available for the time period from 1979 to 2006 with the exception of the years 1979, 1984 and 1985. For these missing years, Chl $a$ concentrations were calculated from measurements of algal biovolume using conversion factors established for Lake Constance on sampling dates when both $\mathrm{Chl} a$ and algal biovolume data were available.

\section{Materials and methods}

\section{The model}

The model used in this study is a modified version of a recently developed hydrodynamically driven phytoplankton model (Peeters et al., 2007). Compared with similar hydrodynamically driven phytoplankton models (Huisman et al., 2002, 2006), the model used here includes a more realistic representation of turbulent mixing that is able to take into account temporal and vertical variations in turbulent diffusive transport, which is essential for the simulation of seasonal phyto- 
plankton development under field conditions in deep lakes. The overall model consists of two components: a one-dimensional hydrodynamic model that simulates vertical profiles of water temperature and turbulent diffusivity in lakes, and a one-dimensional phytoplankton-growth model that can be driven by the output from the hydrodynamic model. The combined model has been described in detail by Peeters et al. (2007); here, we provide only a brief description of its structure and summarize the application and calibration procedures used.

The hydrodynamic model. The hydrodynamic model used was SIMSTRAT, a one-dimensional $k-\varepsilon$ model developed to simulate vertical diffusion and thermal stratification in lakes (Goudsmit et al., 2002; Peeters et al., 2002). SIMSTRAT calculates the energy fluxes across the air/water interface from the given meteorological driving variables, and estimates the turbulent kinetic energy, $k$, and the rate of turbulent kinetic energy dissipation, $\varepsilon$, at different depths within the lake. Turbulent diffusivity $K_{z}$ is estimated from the proportionality $K_{z} \sim k^{2} / \varepsilon$. Water temperature and density profiles are calculated based on the heat flux across the air-water interface, the short-wave radiation penetrating into the lake and the vertical profile of $K_{z}$. Because the simulated temperature profiles reflect the model estimates of vertical diffusive transport, they can be used to calibrate and validate the behaviour of the model with respect to turbulent diffusion.

SIMSTRAT was calibrated by adjusting five constant model parameters to minimize the root-mean-square error between simulated and measured water temperatures during the 6-year time period from 1979 to 1984 (for details see Peeters et al., 2007). In SIMSTRAT, which uses an implicit algorithm to solve the model equations, an internal vertical spatial resolution of $0.25 \mathrm{~m}$ and a time step of $10 \mathrm{~min}$ were used. All simulations were started in 1979 and were run continuously to predict vertical profiles of temperature and turbulent diffusivity from 1987 to 1994. The predicted temperature profiles agree very well with the measured temperatures in Upper Lake Constance and adequately describe the timing of the onset of stratification in spring (Peeters et al., 2007).

From SIMSTRAT, hourly profiles of turbulent diffusivity and temperature with a vertical resolution of $1 \mathrm{~m}$ were obtained. These profiles served as input to the phytoplankton model.

The phytoplankton model. The phytoplankton is modelled in a one-dimensional vertical water column of unit surface area. The vertical distribution of the concentration of algal biomass, $C_{\mathrm{alg}}$ is calculated from production, respiration and vertical transport as follows:

$$
\begin{aligned}
\frac{\partial C_{\mathrm{alg}}}{\partial t} & =\text { production }- \text { losses }+ \text { transport } \\
& =P \gamma C_{\mathrm{alg}}-R \gamma C_{\mathrm{alg}}+\frac{\partial}{\partial z}\left(K_{z} \frac{\partial C_{\mathrm{alg}}}{\partial z}\right)-v_{\mathrm{sed}} \frac{\partial C_{\mathrm{alg}}}{\partial z},
\end{aligned}
$$

where $P$ is the specific production rate. Instead of the Blackman equation (Blackman, 1905) used by Peeters et al. (2007), we use here the hyperbolic tangent function of Jassby \& Platt (1976) to simulate phytoplankton production as function of light intensity (see Table 1). $R$ is the specific respiration rate, which depends on $P . K_{z}$ is the vertical turbulent diffusivity, $v_{\text {sed }}$ the sinking velocity of the algae, $\gamma$ the ratio of $\mathrm{Chl} a$ to algal biomass, and $z$ water depth (positive downwards). The light intensity $I$ is assumed to decrease with depth according to the Lambert-Beer law

$$
I(z)=I_{o} \exp \left(-\int_{0}^{z} \eta\left(z^{\prime}\right) \mathrm{d} z^{\prime}\right),
$$

Table 1 Model equations

Rate of change of the concentration of algal biomass with time:

$$
\begin{aligned}
\frac{\partial C_{\mathrm{alg}}}{\partial t}= & P(I(z), T(z)) \gamma C_{\mathrm{alg}}-R(P(z)) \gamma C_{\mathrm{alg}} \\
& +\frac{\partial}{\partial z}\left(K_{z}(z) \frac{\partial C_{\mathrm{alg}}}{\partial z}\right)-v_{\mathrm{sed}} \frac{\partial C_{\mathrm{alg}}}{\partial z}
\end{aligned}
$$

Specific production rate:

$$
P(I(z), T(z))=P_{\max }(T(z)) \tanh \left(\frac{\alpha I(z)}{P_{\max }(T(z))}\right)
$$

Maximum specific production rate with $T$ in ${ }^{\circ} \mathrm{C}$ :

$$
P_{\max }(T(z))=P_{\max }^{10} Q_{10}^{\left(T(z) / 10^{\circ} \mathrm{C}-1\right)}
$$

Light intensity as a function of depth:

$$
I(z)=I_{o} \exp \left(-\int_{0}^{z} \eta\left(z^{\prime}\right) \mathrm{d} z^{\prime}\right)
$$

Light extinction coefficient as a function of $\mathrm{Chl} a$ concentration:

$$
\eta(z)=\eta_{p}+k_{\mathrm{Chl} a} C_{\mathrm{Chl} a}(z)=\eta_{p}+k_{\mathrm{Chl} a} C_{\mathrm{alg}}(z) / \gamma
$$

Specific respiration rate as a function of the production, water temperature in ${ }^{\circ} \mathrm{C}$ and concentration of algal biomass:

$$
R(P(z))=\frac{1}{\gamma} b_{r} Q_{10}^{\left(T(z) / 10^{\circ} \mathrm{C}-0.5\right)}+p_{r} P(z)
$$

Chl $a$, chlorophyll $a$. 
where $I_{o}$, the photosynthetically active radiation entering the water column at the lake surface, was calculated from measured short-wave radiation data. The light absorption coefficient $\eta$ depends on the concentration of algae, as in similar phytoplankton models (e.g. Huisman et al., 2002, 2006). Vertical profiles of water temperature and turbulent diffusivity were obtained by linear interpolation of the output from the hydrodynamic model to the grid points and times required by the phytoplankton model. Because we investigate phytoplankton growth only during winter and spring, light inhibition and nutrient limitation of production are not considered. The assumption that nutrient availability has only a negligible effect on the timing of the onset of phytoplankton growth is supported by the data from Upper Lake Constance, which show that the timing of phytoplankton growth in spring was not correlated with phosphorus concentrations even when the lake was strongly oligotrophic. All model equations, including those for $P, R$ and $\eta$ are provided in Table 1. Overviews of the relevant variables and model parameters are given in Tables 2 and 3, respectively. The phytoplankton model equation was solved numerically using the method of lines and the implicit MATLAB ${ }^{\circledR}$ algorithm ODE15S with dynamic time stepping. The time steps ranged from $1 \mathrm{~s}$ to $1 \mathrm{~h}$.

Table 2 Variables and time-dependent properties of the model

\begin{tabular}{|c|c|c|}
\hline Variable & Unit & Explanation \\
\hline$C_{\mathrm{alg}}$ & $\mathrm{g} C_{\mathrm{alg}} \mathrm{m}^{-3}$ & Concentration of algal biomass \\
\hline$C_{\text {Chl } a}$ & $\mathrm{gChl} a \mathrm{~m}^{-3}$ & Concentration of $\mathrm{Chl} a$ \\
\hline$\eta$ & $\mathrm{m}^{-1}$ & Light attenuation coefficient \\
\hline$I$ & $\mathrm{mmolQm}^{-2}$ day $^{-1}$ & Light intensity (PAR) in the water column \\
\hline$I_{o}$ & $\mathrm{mmolQm}^{-2}$ day $^{-1}$ & 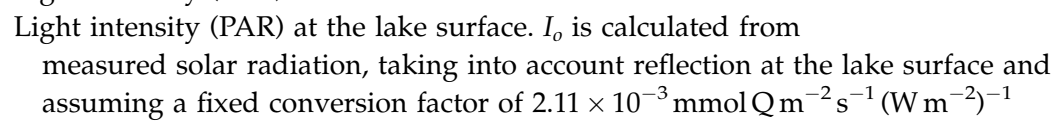 \\
\hline$K_{z}$ & $m^{2}$ day $^{-1}$ & Turbulent diffusivity determined from the hydrodynamic model \\
\hline$P$ & $\mathrm{~g}_{\mathrm{alg}}(\mathrm{gChl} a)^{-1}$ day $^{-1}$ & Specific production rate \\
\hline$P_{\max }$ & $\mathrm{g} C_{\mathrm{alg}}(\mathrm{gChl} a)^{-1}$ day $^{-1}$ & Maximum specific production rate \\
\hline$R$ & $\mathrm{~g} C_{\mathrm{alg}}(\mathrm{gChl} a)^{-1}$ day $^{-1}$ & Specific respiration rate \\
\hline$T$ & ${ }^{\circ} \mathrm{C}$ & Water temperature determined from the hydrodynamic model \\
\hline$z$ & $\mathrm{~m}$ & Depth (positive downwards) \\
\hline
\end{tabular}

PAR, photosynthetically active radiation; $\mathrm{Chl} a$, chlorophyll $a$.

Table 3 Constant model parameters

\begin{tabular}{|c|c|c|}
\hline Parameter & Value and unit & Explanation \\
\hline$\alpha$ & $4.5 \times 10^{-3} \mathrm{~m}^{2} \mathrm{~g} C_{\mathrm{alg}}(\mathrm{gChl} a)^{-1}(\mathrm{mmol} Q)^{-1}$ & Photosynthetic efficiency \\
\hline$b_{\mathrm{r}}$ & $0.01 \mathrm{day}^{-1}$ & Specific base respiration rate at $5^{\circ} \mathrm{C}$ \\
\hline$\gamma$ & $0.05 \mathrm{gChl} a\left(\mathrm{~g} C_{\mathrm{alg}}\right)^{-1}$ & Mass of Chl $a$ per unit phytoplankton biomass (as carbon) \\
\hline$\eta_{p}$ & $0.27 \mathrm{~m}^{-1}$ & $\begin{array}{l}\text { Background light attenuation coefficient of alga-free water in } \\
\text { Upper Lake Constance }\end{array}$ \\
\hline$k_{\mathrm{Chl} a}$ & $0.021 \mathrm{~m}^{2}(\mathrm{mgChl} a)^{-1}$ & Specific light attenuation coefficient of phytoplankton \\
\hline$p_{\mathrm{r}}$ & 0.2 & Fraction of the production required for respiration \\
\hline$P_{\max }^{10}$ & $67.2 \mathrm{~g} \mathrm{C}_{\mathrm{alg}}(\mathrm{g} \mathrm{Chl} a)^{-1} \mathrm{day}^{-1}$ & Maximum specific production rate at $10^{\circ} \mathrm{C}$ \\
\hline$Q_{10}$ & 2.3 & $\begin{array}{l}Q_{10} \text { value for the temperature dependence of the maximum } \\
\text { specific production rate and the specific base respiration rate }\end{array}$ \\
\hline$v_{\text {sed }}$ & $0.1 \mathrm{~m}$ day $^{-1}$ & Sedimentation velocity of phytoplankton \\
\hline
\end{tabular}

Sources of the parameter values used: The values of the parameters $\alpha, P_{\max }^{10}$ and $Q_{10}$ were determined from data measured in Upper Lake Constance (Häse, 1996), as were the values of $\eta_{p}$ and $k_{\mathrm{Chl} a}$ (Tilzer, 1988). Published values of $v_{\text {sed }}$ for Upper Lake Constance range from 0.033 to $1.6 \mathrm{~m} \mathrm{day}^{-1}$ for nine algal species (Sommer, 1984), with the lowest value being for Stephanodiscus hantzschii, which is very common in spring in Upper Lake Constance. Respiration parameters were not determined specifically for Upper Lake Constance, but the values used for $p_{\mathrm{r}}$ and $b_{\mathrm{r}}$ were within the published ranges for these parameters (Geider \& Osborne, 1989). Chl $a$, chlorophyll $a$. 
The internal vertical spatial resolution of the phytoplankton model was $0.25 \mathrm{~m}$. In all simulations the phytoplankton model was always initiated on 1 January of each year.

\section{Scenarios and model operation}

The impact of climate change on physical lake dynamics and phytoplankton growth is simulated by simplified scenarios representing the changes in meteorological conditions that are presumed to occur as a consequence of climate change. The REF is based on measured time series of solar radiation, cloud cover, relative humidity, wind direction, wind speed and air temperature. The climate warming scenarios considered here involve a fixed increase in air temperature of $2{ }^{\circ} \mathrm{C}$ (scenario AT2), $4{ }^{\circ} \mathrm{C}$ (scenario AT4) and $6{ }^{\circ} \mathrm{C}$ (scenario AT6), and a step-like increase in air temperature of $4{ }^{\circ} \mathrm{C}$ (scenario AT4 $4_{\text {step }}$ ), where the air temperature increase is applied beginning on 1 January of the specific year of interest. In addition, we investigate the consequences of increasing and decreasing the wind speed to $120 \%$ (scenario WS12) and $80 \%$ (scenario WS08), respectively, of the value used in scenario REF. These changes in air temperature and wind speed lie within the range predicted to occur in central Europe during the next 100 years (Räisänen et al., 2004). In addition, phytoplankton development was simulated assuming an increase in air temperature of $4{ }^{\circ} \mathrm{C}$ coupled with a simultaneous increase in wind speed to $120 \%$ (scenario AT4WS12). Finally, scenario WT4 was used to investigate the sensitivity of the timing of phytoplankton growth to a change in water temperature. WT4 represents a situation in which water temperatures at all depths are increased by $4{ }^{\circ} \mathrm{C}$, while retaining the turbulent diffusivities of scenario REF.

\section{Statistical analysis}

A statistical analysis was carried out to determine the meteorological conditions associated with the early or late occurrence of the onset of the spring phytoplankton bloom. In this analysis, the time of occurrence of the onset of the spring bloom in each year was estimated as the first sampling date in spring when the mean Chl $a$ concentration within the uppermost $20 \mathrm{~m}$ of the water column exceeded a threshold value of $3 \mathrm{mg} \mathrm{m}^{-3}$. Based on this definition we grouped all years into years of 'early onset' (the 25\% with the earliest onset), 'late onset' (the $25 \%$ with the latest onset) or 'middle onset' (the remaining 50\%). To relate the timing of the phytoplankton bloom to the meteorological conditions prevailing immediately before the onset of the phytoplankton bloom, a bloom-triggered averaging approach
(Freund et al., 2006) was adopted using the following technique. Anomalies of daily mean air temperature, daily sunshine duration and daily maximum wind speed were determined for each day of each year by calculating the deviation of the respective meteorological variable from its mean value for the specific day of the year based on the period 1979-2006. For each year, these daily anomalies were averaged over distinct time periods ( $7,14,21,28,35$ and 42 days) before the onset of the spring phytoplankton bloom. Finally, a $t$-test was used to determine whether these timeaveraged anomalies differ significantly from zero in the early, middle and late bloom years.

\section{Results and discussion}

\section{Numerical simulations}

Compared with the REF, a simulation based on scenario AT4 results in higher water temperatures throughout the water column (Fig. 1a and b). The increase in water temperature in the uppermost $20 \mathrm{~m}$ (Fig. 1b) is only slightly less than the $4{ }^{\circ} \mathrm{C}$ increase in air temperature assumed in scenario AT4. In April the increase in water temperature even exceeds $4{ }^{\circ} \mathrm{C}$ because the model predicts an earlier onset of stratification in a warmer climate. The increase in water temperature is particularly pronounced in the time period between the onset of stratification in the warmer climate and in the reference climate. Simulations of the effect of climate warming on water temperatures in Lake Zurich, $\sim 70 \mathrm{~km}$ from Upper Lake Constance, have suggested that the increase in surface water temperature will be less than the increase in air temperature (Peeters et al., 2002). However, this conclusion was based on climate scenarios that assumed a constant atmospheric water vapour pressure. The more realistic assumption adopted in the present study is that relative humidity rather than water vapour pressure will remain constant, because precipitation is predicted to change only slightly in the future (Räisänen et al., 2004; Arbeitskreis KLIWA, 2006). As a consequence, under the warmer climate scenarios the heat loss from the lake due to the flux of latent heat is smaller in the present study than in the previous simulations for Lake Zurich. Regardless of which assumption is adopted, the increase in the mean temperature of the uppermost $20 \mathrm{~m}$ of the water column is predicted to exceed that of the deep water (below $20 \mathrm{~m}$ ), implying that the thermal stability of the water column under scenario AT4 will exceed that under scenario REF (Fig. 1a). This is the case during all seasons (Fig. 1a), suggesting the existence of stratified conditions all year round, a finding consistent with the simulations carried out for Lake Zurich (Peeters et al., 

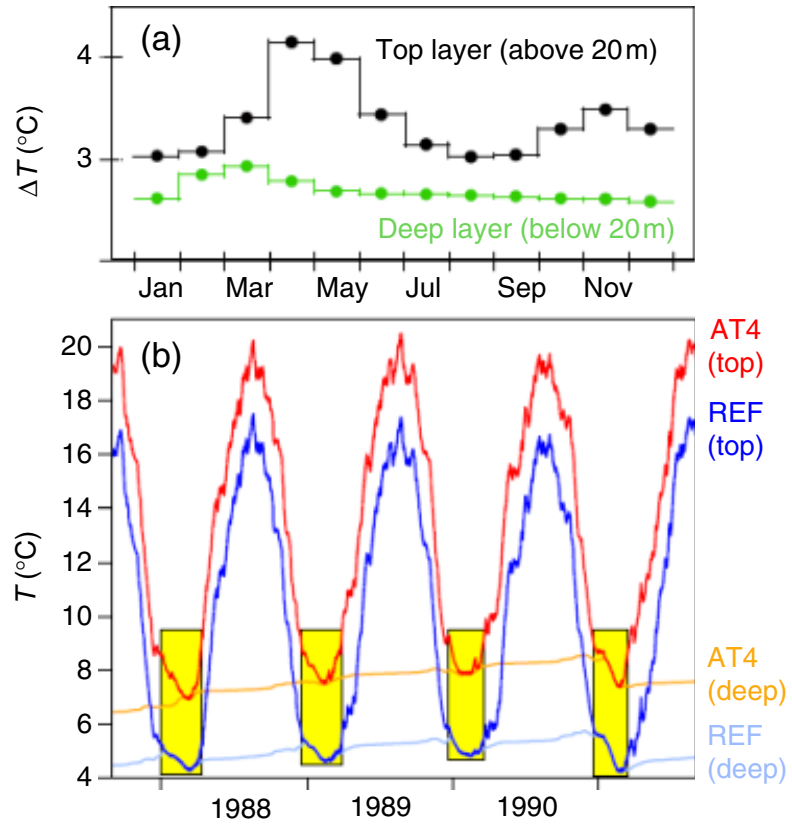

Fig. 1 Impact of climate warming on seasonal water temperature development and stratification. Water temperatures $T$ simulated from measured reference conditions (scenario REF) are compared with those simulated by assuming an increase in air temperature by $4{ }^{\circ} \mathrm{C}$ (scenario AT4). (a) Shows that a $4{ }^{\circ} \mathrm{C}$ increase in air temperature leads to an increase in the monthly mean water temperature in the top layer of the water column (above $20 \mathrm{~m}$ depth, black curve) and in the deep layer (below $20 \mathrm{~m}$ depth, green curve) during the entire year. The illustrated increase in monthly mean water temperature, $\Delta T$, resulting from scenario AT4 was calculated as the difference of the monthly mean temperatures simulated from AT4 and REF averaged over 1987-1994. The temperature variations in the top and deep layers from 1987 to 1992 illustrated in (b) indicate that the duration of homothermy will decrease in a warmer climate; i.e., when AT4 is used to drive the model rather than REF, the time during which the top and deep layers have the same temperature [highlighted yellow for scenario REF in (b)] decreases. REF, reference simulation.

2002). However, Fig. 1a is based only on monthly mean values. In more temporal detail, the simulations of the temperature regime in Upper Lake Constance for the years 1987-1994 reveal that thermal stability decreases to zero during the coldest part of winter under all scenarios, indicating that complete vertical mixing may potentially still occur (Figs $1 \mathrm{~b}$ and $2 \mathrm{a}-\mathrm{c}$ ). Note that under scenario REF the annual minimum water temperature increases from 1987 to 1990 (Fig. 1b). This simulation faithfully reflects the actual situation that occurred at that time not only in Upper Lake Constance itself (Straile et al., 2003), but also in many other lakes in the region (Livingstone, 1997), mainly as a result of a highly positive winter NAO index in 1989 and 1990 that

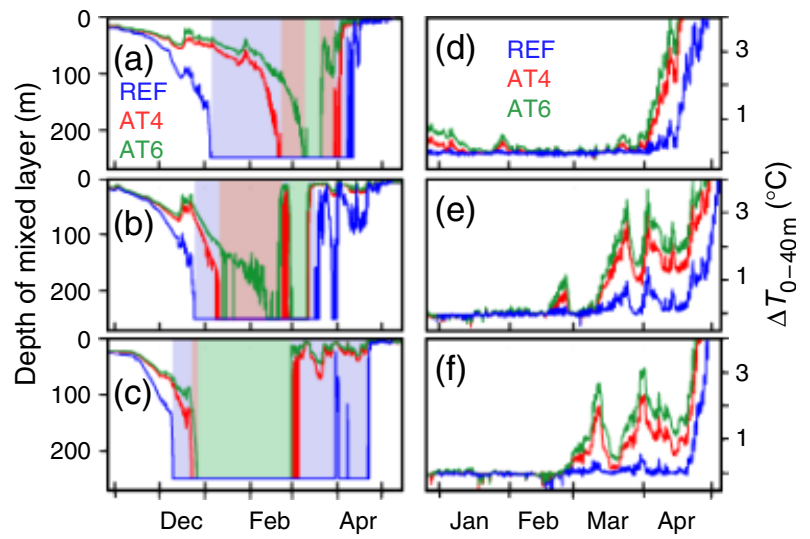

Fig. 2 Impact of climate warming on water temperature and stratification during winter and spring. Simulations of stratification based on measured reference conditions (scenario REF) are compared with simulations assuming an increase in air temperature by $4{ }^{\circ} \mathrm{C}$ (scenario AT4) and $6^{\circ} \mathrm{C}$ (scenario AT6). (a-c) Variations in the thickness of the surface mixed layer in 1988, 1990 and 1994. The mixed layer is defined here as the layer within which the temperature differs from the surface temperature by $<0.5^{\circ} \mathrm{C}$. The greater the shift in air temperature, the shorter is the period of homothermy (shaded areas: blue, red and green correspond to scenarios REF, AT4 and AT6, respectively). $(\mathrm{d}-\mathrm{f})$ The temperature difference between 0 and $40 \mathrm{~m}\left(\Delta T_{0-40 \mathrm{~m}}\right)$ during spring in 1988, 1990 and 1994 is shown for scenarios REF (blue), AT4 (red) and AT6 (green). An increase in $\Delta T_{0-40 \mathrm{~m}}$ indicates the development of stratification within the top $40 \mathrm{~m}$ of the water column, where sufficient light is available to allow phytoplankton growth. REF, reference simulation.

affected not only temperature stratification but also phytoplankton populations in lakes throughout Europe (Weyhenmeyer et al., 2002). This demonstrates that the model adequately describes the response of lake dynamics to changes in large-scale climatic conditions. According to the model, an increase in air temperature leads to a decrease in the duration of the period of complete homothermy (Fig. 2a-c), and hence to an increase in the duration of the period of stratification. In most years the delay in the onset of homothermy induced by climate warming in winter exceeds the concomitant shift towards earlier onset of stratification in spring (Fig. 2a-c). This agrees with calculations based on historical data from Lake Zurich (Livingstone, 2003). Nevertheless, increasing air temperatures do result in the earlier onset of spring stratification, as demonstrated by the behaviour of the simulated temperature difference between 0 and $40 \mathrm{~m}$ depth, $\Delta T_{0-40 \mathrm{~m}}$ (Fig. $2 \mathrm{~d}-\mathrm{f}$ ), which can be considered as a measure of the degree of thermal stratification existing in the upper $40 \mathrm{~m}$ of the water column (Peeters et al., 2007). 

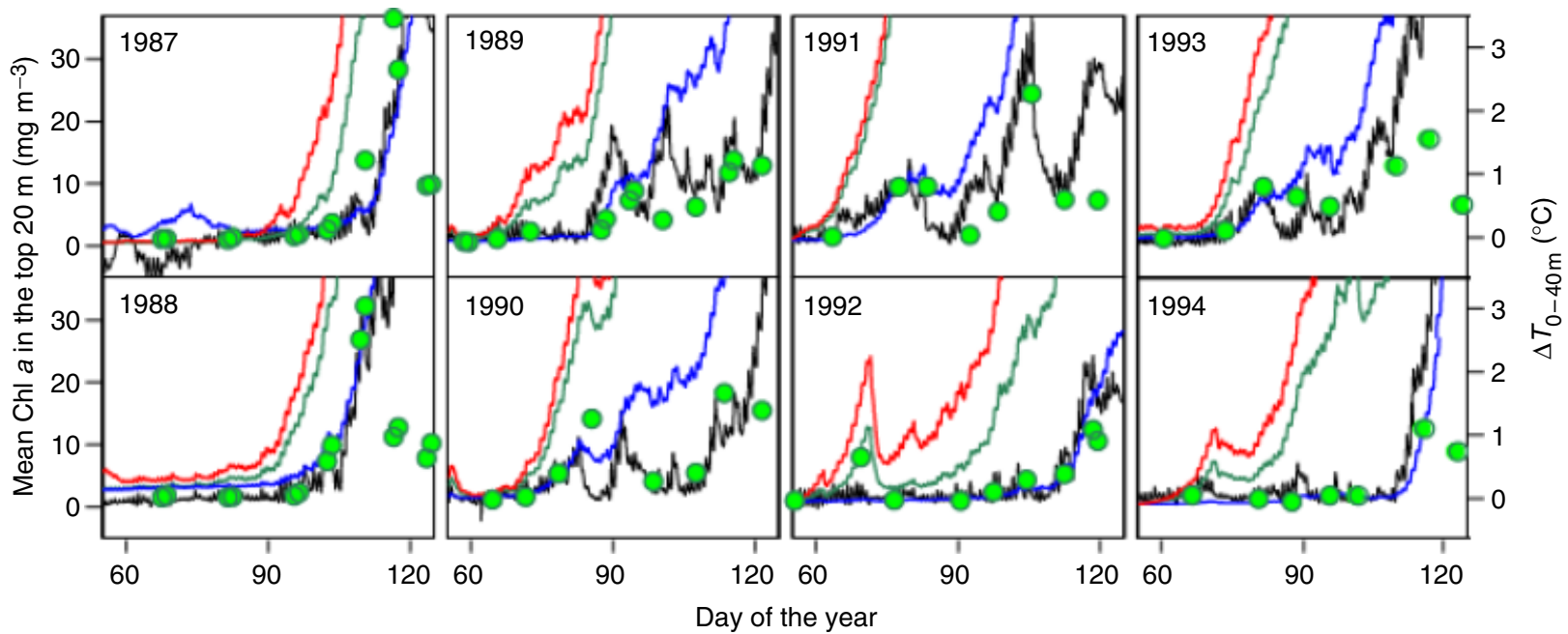

Fig. 3 Impact of climate warming on the timing of the onset of phytoplankton growth in spring. The onset of the increase in the mean measured chlorophyll $a(\mathrm{Chl} a)$ concentration in the uppermost $20 \mathrm{~m}$ of the water column in spring (green symbols, left axis) occurs when $\Delta T_{0-40 \mathrm{~m}}$ (black line, right axis) increases to $\sim 0.5^{\circ} \mathrm{C}$. The timing of the onset of phytoplankton growth simulated under scenario REF (blue line) agrees well with the timing observed in the field (symbols) and adequately reproduces the interannual variability of the data. Simulations based on scenario AT4 (red line) indicate that increased air temperatures lead to the earlier onset of phytoplankton growth. However, the shift in the onset of phytoplankton growth is less than that resulting from scenario AT4 if the air temperature is increased only on 1 January of the specific year of interest (scenario AT4 $4_{\text {step }}$ green line). Chl $a$ was calculated from the simulated values of $C_{\text {alg }}$ using Chl $a=\gamma C_{\mathrm{alg}}$ with $\gamma=0.05 \mathrm{~g} \mathrm{Chl} a\left(\mathrm{~g} \mathrm{C}_{\mathrm{alg}}\right)^{-1}$. Note that the model does not consider nutrient limitation of production and losses by zooplankton grazing and hence overestimates $\mathrm{Chl} a$ concentrations after the onset of phytoplankton growth.

In all years, the abrupt increase in $\Delta T_{0-40 \mathrm{~m}}$ in spring and the steep increase in the mean Chl $a$ concentration occur simultaneously (Fig. 3), indicating that the onset of the spring phytoplankton bloom and the onset of stratification are both triggered by the same process, namely the transition from strong to weak mixing in the upper layers of the lake (Peeters et al., 2007). Because climate warming results in an earlier transition from strong to weak mixing, as is indicated by the earlier development of stratification (Fig. 2d-f), it will also result in the earlier onset of phytoplankton growth in spring (Fig. 3). Also, spring phytoplankton growth in all years starts earlier under scenario AT4 than under scenario $\mathrm{AT} 4_{\text {step, }}$ suggesting that a long-term shift in air temperature induces a shift in the timing of the onset of the spring phytoplankton bloom which is slightly greater than the shifts induced merely by interannual variations in air temperature (Fig. 3). However, in both scenarios, AT4 and AT4 $4_{\text {step }}$ the onset of stratification is shifted significantly to earlier times of the year. In spite of the sudden shift in air temperature in scenario AT4 $4_{\text {step }}$, convective mixing and unstratified conditions prevail during winter and early spring because the heat flux is still often negative during this time period. The model predicts that under scenario AT4 $4_{\text {step }}$, the water temperature in the uppermost $20 \mathrm{~m}$ of the water column is on average $2{ }^{\circ} \mathrm{C}$ lower during the first 120 days of each year than under scenario AT4. The difference in the surface water temperatures between scenarios AT4 and AT4 step decreases significantly only after the onset of stratification during summer and autumn.

Assuming a constant shift in air temperature, the larger the increase in air temperature, the earlier is the onset of both stratification (Fig. $2 \mathrm{~d}-\mathrm{f}$ ) and the spring phytoplankton bloom (Fig. 4). Note that an increase in water temperature alone has only a slight effect on the timing of the onset of the spring phytoplankton bloom (Peeters et al., 2007). Figure 4 demonstrates that the shift in the timing of the onset of phytoplankton growth induced by a warmer climate (Fig. 4, AT4) is not primarily a consequence of the increased water temperature (Fig. 4, WT4), but is caused predominantly by the temporal shift in the transition from strong to weak mixing, as is indicated by the shift in the establishment of stratified conditions (Fig. 2d).

In comparison to the impact of a change in air temperature, the anticipated change in wind speed leads to a much smaller shift in the timing of the onset of spring phytoplankton growth (Fig. 4). Because mixing increases with increasing wind speed, low wind speeds lead to an early onset of the spring phytoplankton bloom (Fig. 4, scenario WS08), while high wind speeds lead to a late onset of the spring phytoplankton 


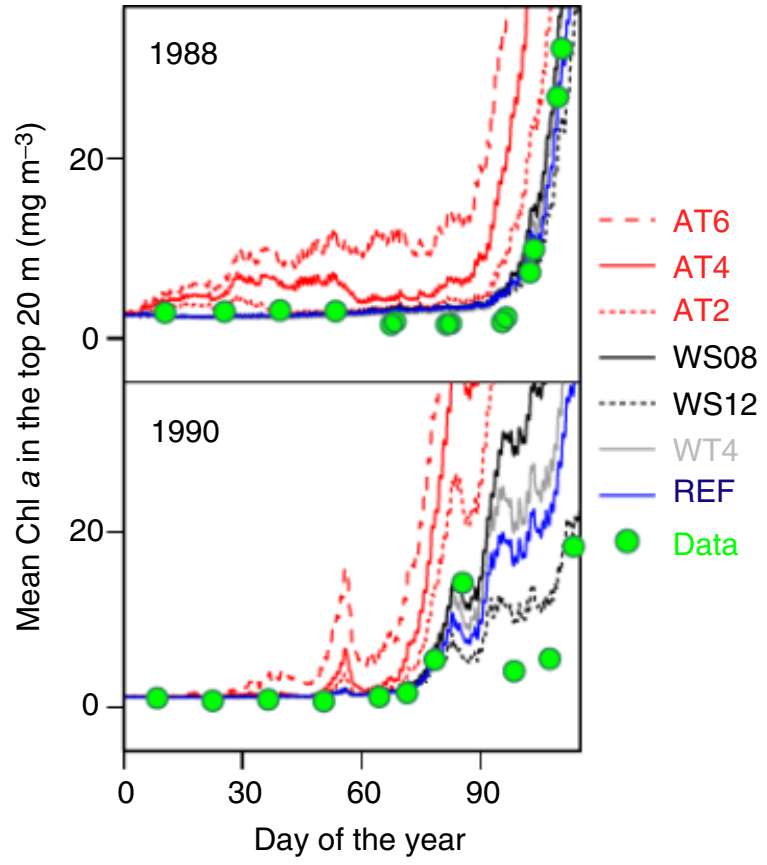

Fig. 4 Sensitivity of the model response to shifts in air temperature, water temperature and wind speed. Simulations of $\mathrm{Chl}$ $a$ concentrations were based on scenarios involving shifts in air temperature with respect to the reference scenario of $+2,+4$ and $+6{ }^{\circ} \mathrm{C}$ (scenarios AT2, AT4 and AT6, respectively: red lines) and scenarios with wind speeds scaled to $80 \%$ and $120 \%$ of measured speeds (scenarios WS08 and WS12, respectively: black lines). The measured data (green symbols) and the simulation based on the reference scenario REF (blue line) are included for comparison. Simulations in which the reference meteorology was used to drive the hydrodynamic model, but the water temperatures were increased by $4{ }^{\circ} \mathrm{C}$ in the phytoplankton model (scenario WT4: grey line), indicate that the temporal shift in the onset of phytoplankton growth induced by climate warming is not caused primarily by the increase in water temperature, but by changes in turbulent vertical mixing. REF, reference simulation.

bloom (Fig. 4, scenario WS12). However, an increase in wind speed to $120 \%$ of its reference value cannot counteract the shift in the onset of phytoplankton growth that is induced by a $4{ }^{\circ} \mathrm{C}$ increase in air temperature. Simulations based on scenario AT4WS12 result in a development of $\mathrm{Chl} a$ that agrees very well with that based on scenario AT4 $4_{\text {step }}$ (the green line in Fig. 3), suggesting a substantial shift in the onset of the spring phytoplankton bloom to earlier times of the year despite the increase in wind speed assumed in this scenario.

Simulations based on scenario AT6 suggest the existence of unusually high phytoplankton concentrations during the entire winter season; e.g., in the winter of 1987/1988 (Fig. 4, AT6). The high phytoplankton abun- dances during winter and spring 1988 resulted from the late onset of homothermy and the comparatively shallow mixing depths attained (Fig. 2a and d), which allowed a net growth of phytoplankton. The occurrence of such a phenomenon may result in an increased abundance of overwintering zooplankton, and thus may affect phytoplankton-growth rates when the annual spring plankton succession begins anew. In addition, it could result in changes to the life history of the zooplankton by affecting the importance of reproduction from resting eggs (Jankowski \& Straile, 2003).

Statistical analysis. Over the past few decades, the phytoplankton in most lakes has been affected not only by changes in climatic conditions, but also by anthropogenic activities in the catchment areas of the lakes - especially activities resulting in the release of nutrients. In Lake Constance, as in the vast majority of temperate lakes, phosphorus is the limiting nutrient (Wetzel, 2001). In Upper Lake Constance, the concentration of total phosphorus averaged over the entire water column during winter mixis decreased from a maximum of $87 \mathrm{mg} \mathrm{Pm}^{-3}$ in 1979 to $<10 \mathrm{mg} \mathrm{Pm}^{-3}$ in 2005 (IGKB, 2005). During winter mixis, particulate phosphorus accounts for only a small fraction of total phosphorus; additionally, $\mathrm{Chl} a$ concentrations during winter mixis showed no significant long-term change. The long-term decrease in total phosphorus can therefore be interpreted as a decrease in soluble reactive phosphorus. In response to this long-term reduction in nutrient levels, the annual maximum of the mean chlorophyll concentration in the uppermost $20 \mathrm{~m}$ of the lake declined from between 40 and $90 \mathrm{mg} \mathrm{m}^{-3}$ in the $1980 \mathrm{~s}$ to approximately $10 \mathrm{mg} \mathrm{m}^{-3}$ since 2000 (D. Straile, unpublished data). Nevertheless, the timing of the onset of phytoplankton growth in spring did not change systematically with time $\left(n=28, r^{2}=-0.04, P=0.31\right)$ and is not related to the mean total phosphorus concentration during mixis ( $n=28, r^{2}=0.08, P=0.13$ ) (Fig. 5). In this statistical analysis, the time of onset of the phytoplankton bloom in a given year was defined as the Julian day on which the mean Chl $a$ concentration in the uppermost $20 \mathrm{~m}$ of the lake first exceeded $3 \mathrm{mg} \mathrm{m}^{-3}$. Similar results were obtained when other absolute thresholds for $\mathrm{Chl} a$ were used, or when the thresholds were defined as a certain percentage of the peak $\mathrm{Chl} a$ in a given year. The insensitivity of the timing of phytoplankton growth to the total phosphorus concentration is actually not surprising, because phytoplankton growth starts after the winter mixing phase, during which the vertical phosphorus distribution is homogenized. The winter mixing makes sufficient phosphorus available to the phytoplankton for its growth to be limited by light 


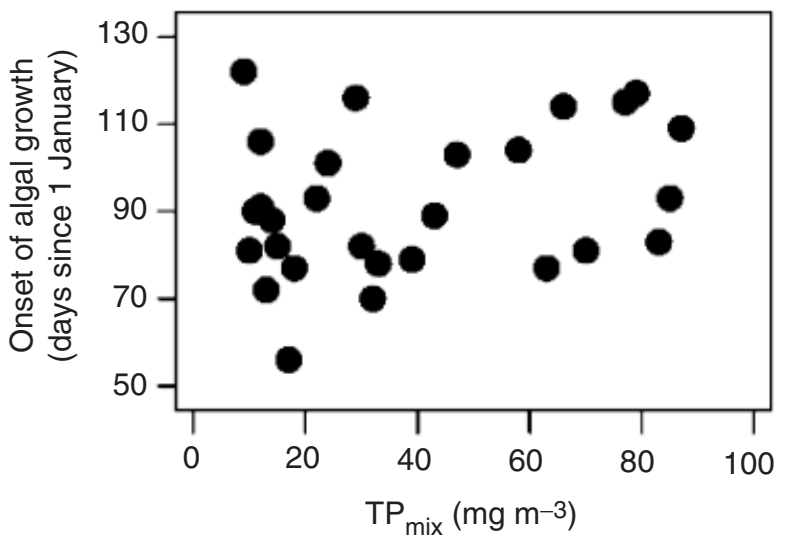

Fig. 5 Total phosphorus concentration and the timing of spring phytoplankton growth. The timing of the onset of phytoplankton growth is plotted vs. the total phosphorus concentration during winter mixis $\left(\mathrm{TP}_{\text {mix }}\right)$ of the same year in Lake Constance. The data shown cover the years 1979-2006 $\left(n=28, r^{2}=0.08\right.$, $P=0.13$ ).

rather than nutrients. When vertical mixing is slow, the phytoplankton begins to grow and take up phosphorus, which is incorporated into the phytoplankton biomass; additionally, the slow vertical mixing means that the phosphorus lost is not replaced from deeper regions of the lake, and phosphorus concentrations within the photolytic zone decline. Although the maximum phytoplankton biomass is affected by nutrients, the timing of the onset of the phytoplankton bloom is not, because it is the phytoplankton growth itself which induces the decline in phosphorus concentration that may finally result in primary production being limited by phosphorus availability (e.g. Weisse $e t$ al., 1990).

The above-mentioned three categories of early, middle and late onset of phytoplankton growth correspond to 25 February to 20 March with a median date of 18 March (early); 22 March to 14 April with a median date of 31 March (middle) and 16 April to 2 May with a median date of 25 April (late). Statistical analysis of the timing of phytoplankton development in spring suggests that early onset of phytoplankton growth is associated with both high air temperatures and low wind speeds during the week before the onset of the spring phytoplankton bloom (Fig. 6a and c). The air temperature anomaly associated with an early onset of phytoplankton growth is only a few degrees celsius. This shows that the long-term data from Lake Constance are consistent with the prediction of the model that a temperature increase of this magnitude can suffice to cause earlier onset of the spring phytoplankton bloom.

The timing of phytoplankton growth in spring is affected not only by air temperature, but also by wind speed. The mean maximum wind speed 7 days before the onset of the bloom, $u_{\max , 7 \text { days, }}$ is approximately $40 \%$ higher in years in which the phytoplankton bloom was late than in years in which it was early (Fig. 6). For individual years, the difference in $u_{\max , 7}$ days can substantially exceed $40 \%$. Hence, the interannual variability of maximum wind speeds is considerably greater than the average 20\% change in wind speed predicted for the Lake Constance region based on global climate change scenarios. The interannual variability in wind speed therefore has a greater influence on the timing of the onset of the spring phytoplankton bloom than does the mean change in wind speed anticipated from global climate change scenarios. Assuming that the interannual variability in wind speed is not affected by climatic warming, our numerical simulations consistently suggest that in a warmer world, the interannual variability in the onset of phytoplankton growth will remain much as it is today. However, as a consequence of the increase in air temperature and the related shift in the timing of the transition from strong to weak vertical mixing, the onset of phytoplankton blooms will, on average, be shifted to an earlier time of the year.

Note that our statistical results with respect to temperature only hold if the threshold value used to define the onset of the spring phytoplankton bloom is sufficiently large so that the early, small phytoplankton blooms that develop in the very few years with inverse stratification are below the threshold value of $3 \mathrm{mg} \mathrm{m}^{-3}$ mean Chl $a$ (and thus are not taken as the true time of the onset of the spring phytoplankton bloom). These latter, very early blooms can clearly occur only when both air temperature and wind speed are very low, as this is a requirement for the development of inverse stratification. An increase in the duration of the time period over which the meteorological factors are averaged leads to a decrease in the mean magnitude of the anomalies associated with early phytoplankton blooms. Thus, 1 week of positive air temperature anomalies and negative maximum wind speed anomalies suffices to induce early onset of the spring phytoplankton bloom, and the meteorological conditions existing 3 or 4 weeks before the bloom seem not to be relevant. Late onset of the spring phytoplankton bloom, however, is not associated with high winds over a short period of time, but with the prevalence of positive daily maximum wind speed anomalies over a long time period ( $>3$ weeks) (Fig. 6c). In contrast to air temperature and wind speed, sunshine duration apparently has no influence on the timing of the onset of phytoplankton growth (Fig. 6b), which would therefore appear to be determined by a complex interaction between air temperature and wind speed, in which not only the magnitude of these variables, but 

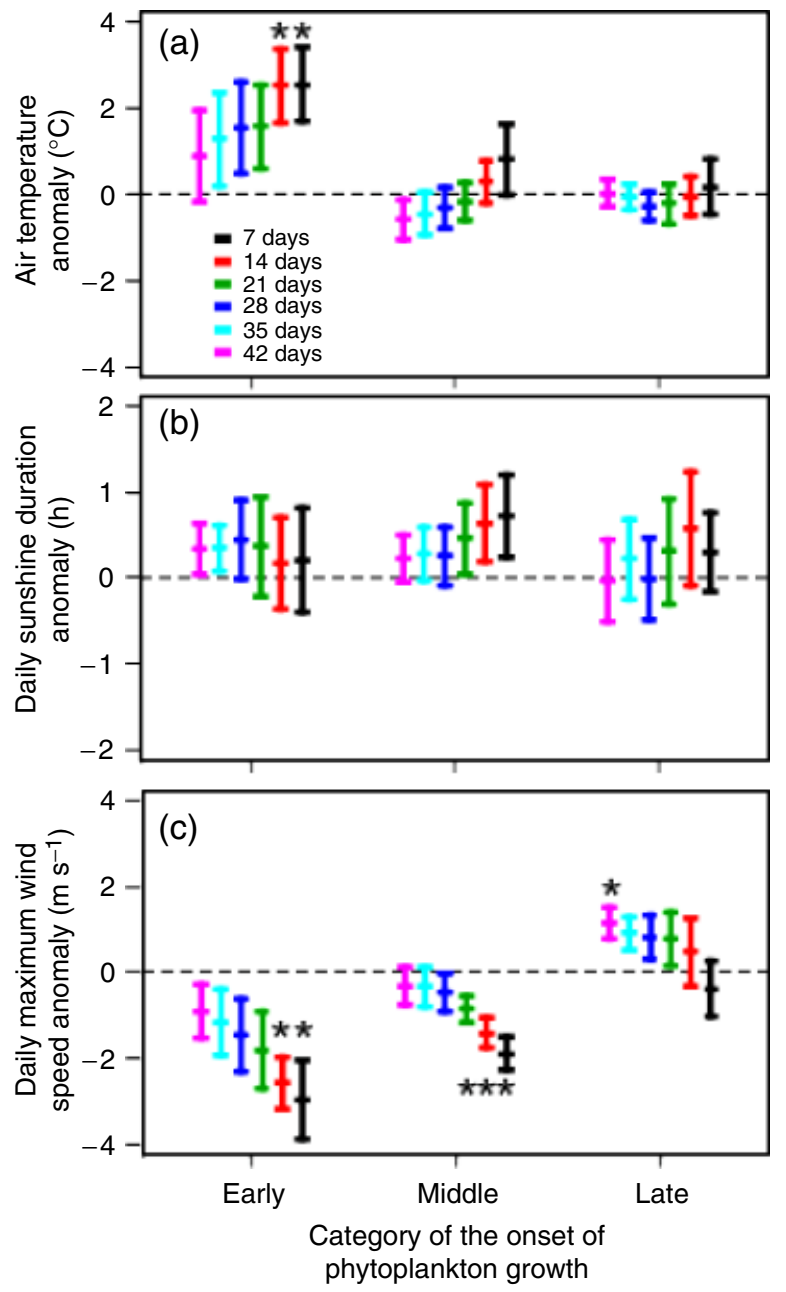

Fig. 6 Anomalies of air temperature, sunshine duration and maximum daily wind speed during years with early (1st quartile), middle (second and third quartiles) and late (fourth quartile) onset of the spring phytoplankton bloom. The anomalies of the meteorological variables were averaged over six different time periods $(7,14,21,28,35$ and 42 days) immediately preceding the onset of the spring phytoplankton bloom in each year. The three categories of early, middle and late onset of the phytoplankton bloom correspond to 25 February to 20 March with a median date of 18 March (early); 22 March to 14 April with a median date of 31 March (middle) and 16 April to 2 May with a median date of 25 April (late). Errors bars denote one standard error of the mean. Asterisks indicate time periods during which the anomalies differ significantly from zero. Note that the number of observations in the middle category is twice the number of observations in the other two categories, resulting in a higher statistical power for this category. A difference of $2 \mathrm{~m} \mathrm{~s}^{-1}$ in the mean anomaly of the maximum wind speed corresponds to about $40 \%$.

also their timing, is important. The same conclusion can be drawn from the numerical modelling study. According to previous simulation results, interannual variations in the timing of phytoplankton growth result from interannual variations in the timing of the transition from strong to weak mixing (Peeters et al., 2007). Although high air temperatures favour the development of stratified conditions with weak vertical mixing, wind events can compensate for this effect by mixing the weakly stratified water column. Clearly, mixing intensity and the timing of mixing events does not only depend on the absolute values of air temperature and wind speed, but also on the timing of wind events in relation to time periods with high or low air temperatures. Because the timing of wind events varies in a very irregular fashion from year to year, interannual variations in the timing of the onset of the spring phytoplankton bloom cannot be related in a simple fashion to air temperature and wind speed without including specific information on the relative timing of extreme events.

Conclusions and implications. The numerical simulations presented above predict that a systematic increase of $4{ }^{\circ} \mathrm{C}$ in air temperature will result in a significantly earlier onset of the spring phytoplankton bloom in Upper Lake Constance. This can be expected also to apply to other deep lakes in the temperate zone, and may also apply to the temperate ocean. Upper Lake Constance does not normally freeze over in winter. In lakes that do freeze over, however, climate warming is likely to affect the timing of the onset of phytoplankton growth even more strongly. This is because in icecovered lakes, the timing of the reduction in the intensity of vertical mixing that occurs with the onset of stratification is tightly linked to the timing of ice break-up. This, in its turn, is highly dependent on air temperature (e.g. Ruosteenoja, 1986; Vavrus et al., 1996), and therefore reacts sensitively to long-term climate warming (Magnuson et al., 2000). At lower latitudes, even shallow lakes do not freeze over, so that phytoplankton development in winter and spring is limited by lake depth rather than mixing intensity. In such lakes, climate warming is likely to have much less effect on the timing of the onset of phytoplankton growth than in Upper Lake Constance.

The predictions of the impact of climate warming on the timing of phytoplankton growth in Upper Lake Constance are likely to be valid if wind speeds remain the same as those that prevailed from 1987 to 1994, or even if they increase by up to $20 \%$. However, if the pattern of high wind events were also to change in the future, with, for instance, storms occurring more frequently in spring, the shift in the onset of the spring phytoplankton blooms might not be as strong as that predicted from the scenarios assumed above. Unfortunately, the future pattern of high wind events on a regional scale is very difficult to predict, and a 
reliable prognosis of the wind speed that is likely to prevail in a future warmer climate is not yet available for the Lake Constance area.

Climate warming is predicted to induce a shift not only in the timing of the onset of the growth of phytoplankton, but also in that of Daphnia populations (Scheffer et al., 2001). These shifts, however, are caused by different mechanisms: in the case of phytoplankton, it is the earlier transition from strong to weak vertical mixing that causes the shift, as demonstrated above; whereas in the case of Daphnia, it is the increase in water temperature (Straile, 2000). This difference in the mechanisms responsible makes it unlikely that climate warming will result in the same temporal shift in the onset of the growth of both the phytoplankton and the Daphnia populations. Before daphnids become the dominant grazers, other zooplankton taxa, such as ciliates in the case of Lake Constance (Weisse et al., 1990; Gaedke et al., 2002), are responsible for phytoplankton loss. Because these zooplankton taxa have grazing and population growth rates that differ from those of daphnids, a shift in the timing of phytoplankton growth will thus have important consequences for zooplankton community structure.

Because the effect of climate warming on lake plankton community structure over the past few decades has been effectively masked by strong, direct, anthropogenic impacts - e.g. eutrophication and oligotrophication - the response of lake plankton to long-term climate warming is often inferred by analysing its response to interannual fluctuations in climate rather than to the long-term change in climatic forcing (e.g. Straile, 2000). However, as demonstrated above, the shift in the onset of phytoplankton growth in a consistently warmer climate will exceed that resulting from a single unusually warm year. Furthermore, the model predicts that a single year with unusually high air temperatures will result in a smaller change in winter and spring water temperatures than would be expected to result from a consistently warmer climate. Hence, the effect of a warmer climate on food-web interactions in spring - which are sensitive to both water temperature and phytoplankton growth - may exceed the effect anticipated from the results of statistical analyses of the interannual variations in measured time series. This suggests that the consequences of climate warming for aquatic ecosystems may be even more severe than previously thought.

\section{Acknowledgements}

The research described here forms part of the project 'MOPPS' (PE 701/2-1), conducted within the AQUASHIFT programme (SPP 1162), funded by the Deutsche Forschungsgemeinschaft (DFG).
DML was supported by the Swiss Secretariat for Education and Science within the framework of the European Union project Euro-limpacs (GOCE-CT-2003-505540). We thank B. Beese, C. Häse and M. M. Tilzer for the $\mathrm{Chl} a$ data, which were measured within the DFG-funded programme SFB 248 ('The cycling of matter in Lake Constance'). The meteorological data were kindly provided by the German National Meteorological Service (Deutscher Wetterdienst). We thank H. Rossknecht (Institut für Seenforschung, Langenargen) for the long-term temperature data set used for model calibration and for total phosphorus concentrations measured during winter mixis. Constructive comments by an unknown reviewer helped to improve the manuscript.

\section{References}

Adrian R, Walz N, Hintze T, Hoeg S, Rusche R (1999) Effects of ice duration on the plankton succession during spring in a shallow polymictic lake. Freshwater Biology, 41, 621-623.

Arbeitskreis KLIWA (2006) Regionale Klimaszenarien für Süddeutschland. Stork Druckerei $\mathrm{GmbH}$, Bruchsal. (http:// www.kliwa.de/download/KLIWAHeft9.pdf)

Bäuerle E, Gaedke U (eds) (1998) Lake Constance - characterization of an ecosystem in transition. Archiv für Hydrobiologie Advances in Limnology, 53, 610 pp.

Beaugrand G, Brander KM, Lindley JA, Soussi S, Reid PC (2003) Plankton effect on cod recruitment in the North Sea. Nature, 426, 661-664.

Blackman FF (1905) Optima and limiting factors. Annals of Botany, 19, 281-295.

Bleiker W, Schanz F (1989) Influence of environmental factors on the phytoplankton spring bloom in Lake Zurich. Aquatic Sciences, 51, 47-58.

Cushing DH (1990) Plankton production and year-class strength in fish populations: an update of the match/mismatch hypotheses. Advances in Marine Biology, 26, 249-293.

Danis P-A, von Grafenstein U, Masson-Delmotte V, Planton S, Gerdeaux D, Moisselin J-M (2004) Vulnerability of two European lakes in response to future climatic changes. Journal of Geophysical Research, 31, L21507, doi: 21510.21029/22004GL020833.

Freund JA, Mieruch S, Scholze B, Wiltshire K, Feudel U (2006) Bloom dynamics in a seasonally forced phytoplankton-zooplankton model: trigger mechanisms and timing effects. Ecological Complexity, 3, 129-139.

Gaedke U, Hochstädter S, Straile D (2002) Interplay between energy limitation and nutritional deficiency: empirical data and food web models. Ecological Monographs, 72, 251-270.

Geider RJ, Osborne BA (1989) Respiration and microalgal growth: a review of the quantitative relationship between dark respiration and growth. New Phytologist, 112, 327-341.

Goudsmit G-H, Burchard H, Peeters F, Wüest A (2002) Application of $k-\varepsilon$ turbulence models to lakes - the role of internal seiches. Journal of Geophysical Research, 107, 3230-3242.

Güde H, Rossknecht H, Wagner G (1998) Anthropogenic impacts on the trophic state of Lake Constance during the 20th century. Archiv für Hydrobiologie - Advances in Limnology, 53, 85-108.

Häse C (1996) Die Vorhersage der Produktivität des Phytoplanktons im Bodensee unter Berücksichtigung der Temperatur sowie der 
spektralen Zusammensetzung des Unterwasser-Strahlungsfeldes. PhD thesis, University of Konstanz.

Häse C, Gaedke U, Seifried A, Beese B, Tilzer MM (1998) Phytoplankton response to re-oligotrophication in large and deep Lake Constance: photosynthetic rates and chlorophyll concentrations. Archiv für Hydrobiologie - Advances in Limnology, 53, 159-178.

Huisman J, Arrayas K, Ebert U, Sommeijer B (2002) How do sinking phytoplankton species manage to persist? American Naturalist, 159, 245-254.

Huisman J, Thi NNP, Karl DM, Sommeijer B (2006) Reduced mixing generates oscillations and chaos in the oceanic deep chlorophyll maximum. Nature, 439, 322-325.

IGKB (2005) Limnologischer Zustand des Bodensees. Jahresberichte Internationale Gewässerschutzkommission. Bodensee: Limnologischer Zustand, 32, 1-75.

Jankowski T, Straile D (2003) A comparison of egg bank and long-term plankton dynamics of two Daphnia species, $D$. hyalina and D. galeata: potentials and limits of reconstruction. Limnology and Oceanography, 48, 1948-1955.

Jassby AD, Platt T (1976) Mathematical formulation of the relationship between photosynthesis and light for phytoplankton. Limnology and Oceanography, 21, 540-547.

Livingstone DM (1997) An example of the simultaneous occurrence of climate-driven "sawtooth" deep-water warming/ cooling episodes in several Swiss lakes. Verhandlungen der internationalen Vereinigung der Limnologie, 26, 822-826.

Livingstone DM (2003) Impact of secular climate change on the thermal structure of a large temperate central European lake. Climatic Change, 57, 205-225.

Magnuson JJ, Robertson DM, Benson BJ et al. (2000) Historical trends in lake and river ice cover in the Northern Hemisphere. Science, 289, 1743-1746.

Peeters F, Livingstone DM, Goudsmit G-H, Kipfer R, Forster R (2002) Modeling 50 years of historical temperature profiles in a large central European lake. Limnology and Oceanography, 47, 186-197.

Peeters F, Straile D, Lorke A, Ollinger D (2007) Turbulent mixing and phytoplankton spring bloom development in a deep lake. Limnology and Oceanography, 52, 286-298.

Post E, Peterson RO, Stenseth NC, McLaren BE (1999) Ecosystem consequences of wolf behavioural response to climate. Nature, 401, 905-907.

Räisänen J, Hansson U, Ullerstig A et al. (2004) European climate in the late twenty-first century: regional simulations with two driving global models and two forcing scenarios. Climate Dynamics, 22, 13-31.

Ruosteenoja K (1986) The date of break-up of lake ice as a climatic index. Geophysica, 22, 89-99.

Scheffer M, Straile D, van Nes EH, Hosper H (2001) Climatic warming causes regime shifts in lake food webs. Limnology and Oceanography, 46, 1780-1783.
Sharples J, Ross ON, Scott BE, Greenstreet SPR, Fraser H (2006) Inter-annual variability in the timing of stratification and the spring bloom in the North-western North Sea. Continental Shelf Research, 26, 733-751.

Sommer U (1984) Sedimentation of principal phytoplankton species in Lake Constance. Journal of Plankton Research, 6, 1-14. Sommer U (1989) Plankton Ecology. Springer, Berlin.

Stefan HG, Fang X, Hondzo M (1998) Simulated climate change effects on year-round water temperatures in temperate zone lakes. Climatic Change, 40, 547-576.

Stenseth NC, Mysterud A (2002) Climate, changing phenology, and other life history traits: nonlinearity and match-mismatch to the environment. Proceedings of the National Academy of Sciences of the United States of America, 99, 13379-13381.

Straile D (2000) Meteorological forcing of plankton dynamics in a large and deep continental European lake. Oecologia, 122, 44-50.

Straile D, Joehnk K, Rossknecht H (2003) Complex effects of winter warming on the physico-chemical characteristics of a deep lake. Limnology and Oceanography, 48, 1432-1438.

Tian RC, Deibel D, Thompson RJ, Rivkin RB (2003) Modeling of climate forcing on a cold-ocean ecosystem, Conception Bay, Newfoundland. Marine Ecology Progress Series, 262, 1-17.

Tilzer MM (1988) Secci disc - chlorophyll relationships in a lake with highly variable phytoplankton biomass. Hydrobiologia, 162, 163-171.

Vavrus SJ, Wynne RH, Foley JA (1996) Measuring the sensitivity of southern Wisconsin lake ice to climate variations and lake depth using a numerical model. Limnology and Oceanography, 41, 822-831.

Visser ME, Hollemann LJM (2001) Warmer springs disrupt the synchrony of oak and winter moth phenology. Proceedings of the Royal Society of London Series B, 268, 289-294.

Visser ME, van Noordwijk J, Tinbergen JM, Lessels CM (1998) Warmer springs lead to mistimed reproduction in great tits (Parus major). Proceedings of the Royal Society of London Series B, 265, 1867-1870.

Weisse T, Müller H, Pinto-Coelho RM, Schweizer A, Springmann D, Baldringer G (1990) Response of the microbial loop to the phytoplankton spring bloom in a large prealpine lake. Limnology and Oceanography, 35, 781-794.

Wetzel RG (2001) Limnology - Lake and River Ecosystems. Academic Press, San Diego.

Weyhenmeyer GA, Adrian R, Gaedke U, Livingstone DM, Maberly SC (2002) Response of phytoplankton in European lakes to a change in the North Atlantic Oscillation. Verhandlungen der internationalen Vereinigung der Limnologie, 28, 1436-1439.

Winder M, Schindler DE (2004) Climate change uncouples trophic interactions in an aquatic ecosystem. Ecology, 85, 2100-2106. 